studied at their dorsal surface. The ultrasound has objectified the presence of two signs: hyperechoic band over the superficial margin of the articular cartilage described as a double contour (DC) and tophaceous deposits at the joint cavity. Results: The mean age at onset was $54.7 \pm 12,6$ years, and the median diagnosis duration was 0 (0.3) years).

The results of the US examination are summarized in Table 1.

Table 1. Prevalence of ultrasonographic gout specific signs of hind-foot, mid-foot and Metatarsophalangeal joints in the studied population

\begin{tabular}{lcc}
\hline Joints $(\mathrm{N}=330)$ & Double contour $(\%)$ & Tophaceous deposits $(\%)$ \\
\hline Hind-foot & 8,8 & 10 \\
Talocrural $(\mathrm{N}=30)$ & 13,3 & 13,3 \\
Subtalar: & & \\
Lateral $(\mathrm{N}=30)$ & 3,3 & 10 \\
Medial $(\mathrm{N}=30)$ & 10 & 6,7 \\
Mid-foot & 14,4 & 32,2 \\
Talonavicular $(\mathrm{N}=30)$ & 13,3 & 13,3 \\
Intertarsal $(\mathrm{N}=30)$ & 6,7 & 43,3 \\
Tarsometatarsal $(\mathrm{N}=30)$ & 23,3 & 40 \\
MTP $(\mathrm{N}=150)$ & 11,3 & 18 \\
MTP 1 $(\mathrm{N}=30)$ & 33,3 & 56,7 \\
MTP 2 $(\mathrm{N}=30)$ & 13,3 & 13,3 \\
MTP 3 $(\mathrm{N}=30)$ & 6,7 & 3,3 \\
MTP 4 $(\mathrm{N}=30)$ & 0 & 6,7 \\
MTP 5 $(\mathrm{N}=30)$ & 3,3 & 10
\end{tabular}

Conclusions: This study showed a predilection for the gout specific ultrasound signs (DC and tophaceous deposits) in the tarsometatarsal and metatarsophalangeal joints, especially in the first MTP. The contribution of musculoskeletal ultrasound seems to be very interesting to objectify the presence of gout specific signs of the foot joints.

Disclosure of Interest: None declared

DOI: 10.1136/annrheumdis-2017-eular.2468

\section{AB0886 PHARMACOKINETICS, PHARMACODYNAMICS, AND TOLERABILITY OF VERINURAD (RDEA3170), A SELECTIVE URIC ACID REABSORPTION INHIBITOR, IN HEALTHY ADULT MALE SUBJECTS}

M. Gillen ${ }^{1}$, Z. Shen ${ }^{2}$, J.N. Miner ${ }^{2} .{ }^{1}$ AstraZeneca, Gaithersburg, MD; ${ }^{2}$ Ardea Biosciences, Inc., San Diego, CA, United States

Background: Verinurad (RDEA3170) is a selective uric acid reabsorption inhibitor in clinical development for the treatment of gout and asymptomatic hyperuricemia. Objectives: The aim of this study was to evaluate the pharmacokinetics, pharmacodynamics, and tolerability of verinurad following single and multiple doses in healthy adult males.

Methods: This was a Phase 1, randomized, double-blind, placebo-controlled, single- and multiple-ascending dose study. Panels of 8 male subjects (6 active, 2 placebo) received a single oral dose of verinurad or placebo in either a fasted ( $2 \mathrm{mg}, 5 \mathrm{mg}, 20 \mathrm{mg}, 40 \mathrm{mg}$ ) or fed ( $5 \mathrm{mg}, 20 \mathrm{mg}$ ) state and panels of 12 male subjects (9 active, 3 placebo) received ascending doses of once-daily verinurad (1 $\mathrm{mg}, 5 \mathrm{mg}$, and $10 \mathrm{mg}$ ) or placebo in a fasted state for up to 10 days. Verinurad was administered as an oral solution for 1 and $2 \mathrm{mg}$ doses and in tablet form for doses $>2 \mathrm{mg}$. Serial plasma/serum and urine samples were assayed for verinurad and uric acid at predetermined time points. Safety was assessed by adverse event (AE) reports, laboratory tests, vital signs, and electrocardiograms (ECGs).

Results: A total of 81 adult males aged 18-54 years enrolled and completed the study. Following single oral doses of verinurad, absorption was rapid and exposure (maximum plasma concentration $\left[\mathrm{C}_{\max }\right]$ and area under the plasma concentrationtime curve $[\mathrm{AUC}]$ ) increased in a dose-proportional manner up to the maximum dose tested; $\mathrm{C}_{\max }$ was achieved at $0.5-0.75$ hours post-dose in the fasted state, and was slightly delayed to 1.25 hours post-dose in the fed state. Food appeared to decrease AUC by about $23 \%$ and $\mathrm{C}_{\max }$ by about $50 \%$. Following multiple daily doses, there was modest accumulation of verinurad. Urinary excretion of verinurad accounted for approximately $2 \%$ of the administered dose, suggesting that renal excretion is a minor elimination pathway for unchanged verinurad. Reductions in

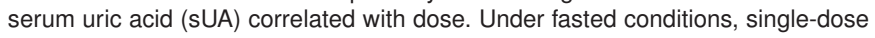
administration of verinurad $2,5,20$, or $40 \mathrm{mg}$ reduced sUA levels by $16 \%, 24 \%$, $48 \%$, and $62 \%$, respectively. Following multiple once-daily dosing for 10 days, verinurad reduced sUA levels by $22 \%, 44 \%$, and $61 \%$ for the 1,5 , and $10 \mathrm{mg}$ doses, respectively. A persistent pharmacologic effect ( $>15 \%$ fractional excretion of uric acid relative to baseline) was evident for at least 24 hours after dosing for verinurad doses of $2 \mathrm{mg}$ or above. Verinurad was well tolerated at all doses. No serious AEs, severe AEs, discontinuations due to AEs or clinically significant laboratory or ECG abnormalities were reported.

Conclusions: Single and multiple doses of verinurad were well tolerated, absorption was rapid and exposure was dose-proportional. Verinurad increased urinary uric acid elimination and resulted in sustained reductions in sUA. These data support further clinical evaluation of once-daily verinurad as a treatment for gout.

Acknowledgements: The authors thank Caroline Lee of Ardea Biosciences, Inc. for critical review of the abstract.
Disclosure of Interest: M. Gillen Employee of: AstraZeneca, Z. Shen Employee of: Ardea Biosciences, Inc., J. Miner Employee of: Ardea Biosciences, Inc. DOI: 10.1136/annrheumdis-2017-eular.5133

\section{AB0887 PHARMACOKINETICS, PHARMACODYNAMICS, AND TOLERABILITY OF VERINURAD (RDEA3170), A SELECTIVE URIC ACID REABSORPTION INHIBITOR, IN HEALTHY JAPANESE MALE SUBJECTS}

M. Gillen ${ }^{1}$, J.N. Miner ${ }^{2}$, S. Valdez ${ }^{2} .{ }^{1}$ AstraZeneca, Gaithersburg, MD; ${ }^{2}$ Ardea Biosciences, Inc., San Diego, CA, United States

Background: Chronic gout is a significant clinical problem in Asia, including Japan, where many patients remain suboptimally treated with currently available therapies. Verinurad (RDEA3170) is a selective uric acid reabsorption inhibitor in clinical development for the treatment of gout and asymptomatic hyperuricemia.

Objectives: The aim of this study was to evaluate the pharmacokinetics, pharmacodynamics, and tolerability of verinurad in healthy Japanese and nonAsian adult male subjects.

Methods: This was a Phase 1, randomized, single-blind, placebo-controlled study (NCT01872832). Panels of 8 Japanese male subjects were randomized in a 3:1 ratio to receive a modified-release formulation of oral verinurad $(2.5 \mathrm{mg}, 5 \mathrm{mg}$, $10 \mathrm{mg}, 15 \mathrm{mg}$ ) or placebo administered as a single dose in a fasted state and as multiple once-daily doses in a fed state for 7 days. A panel of 8 non-Asian male subjects received single and multiple doses of oral verinurad $(10 \mathrm{mg})$ or placebo. Serial plasma/serum and urine samples were assayed for verinurad and uric acid at predetermined time points. Safety was assessed by adverse event (AE) reports, laboratory tests, vital signs, and electrocardiograms (ECGs).

Results: Of 48 randomized subjects, 46 (Japanese: 39, non-Asian: 7) completed the study. Treatment groups were generally well balanced; however, mean body weight and body mass index were approximately $14 \%$ and $7 \%$ lower, respectively, in Japanese than non-Asian subjects. Following single- or multiple-oral doses of verinurad in Japanese subjects, exposure (maximum plasma concentration $\left[\mathrm{C}_{\max }\right]$ and area under the plasma concentration-time curve [AUC]) increased in a near dose-proportional manner under fasted or fed conditions. The time to $\mathrm{C}_{\max }$ ( $T_{\max }$ ) was approximately $1.25-2.0$ hours post-dose under fasted conditions. A moderate-fat meal delayed $\mathrm{T}_{\max }$ up to 5 hours post-dose and increased plasma verinurad exposures up to $109 \%$. Following once-daily multiple doses, there was modest accumulation of verinurad. $\mathrm{C}_{\max }$ and AUC were $38 \%$ and $23 \%$ higher, respectively, in Japanese versus non-Asian subjects, largely due to the difference in body weight. Mean reductions in serum uric acid following once-daily multiple dosing of verinurad $10 \mathrm{mg}$ were $62 \%$ and $58 \%$ at maximum reduction and $46 \%$ and $44 \%$ at 24 hours post-dose in Japanese and non-Asian subjects, respectively. Verinurad was well tolerated at all doses. One Japanese subject discontinued verinurad due to an $A E$ of urticaria that resolved after 11 days. No serious AEs, Grade 3 or $4 \mathrm{AEs}$, or clinically significant laboratory or ECG abnormalities were noted. Conclusions: Verinurad significantly lowered serum uric acid and was well tolerated in both healthy Japanese and non-Asian males, despite small differences in plasma pharmacokinetics. These data support further evaluation of once-daily verinurad as a treatment for hyperuricemia with or without gout in the Japanese population.

Acknowledgements: The authors thank Caroline Lee and Zancong Shen of Ardea Biosciences, Inc., for critical review of the abstract.

Disclosure of Interest: M. Gillen Employee of: AstraZeneca, J. Miner Employee of: Ardea Biosciences, Inc., S. Valdez Employee of: Ardea Biosciences, Inc. DOI: 10.1136/annrheumdis-2017-eular.5200

\section{AB0888 TENOFOVIR INDUCED OSTEOMALACIA: A PROFILE BASED ON THREE PATIENTS WITH LOW PHOSPHORUS AND NORMAL LEVELS OF VITAMIN D AND PARATHYROID HORMONE}

M. Lovy. Desert Oasis Healthcare, Palm Springs, California, United States

Background: Tenofovir can induce proximal renal tubular changes that result in varying expression of Fanconi syndrome ${ }^{1,2}$. Less commonly, osteomalacia related to hypophosphatemia ${ }^{2,3}$ can occur and has been documented with bone biopsy ${ }^{3}$. The clinical details of 28 reported cases of tenofovir induced osteomalacia, some of whom had vitamin D deficiency and secondary hyperparathyroidism, was recently summarized ${ }^{3}$.

Objectives: To describe the clinical presentation and course of three HIV patients with tenofovir induced hypophosphatemic osteomalacia and compare to cases previously reported.

Methods: The clinical, laboratory, and radiologic features of three HIV patients referred for evaluation of pain and osteoporosis were reviewed.

Results: All three patients were male, had diffuse pain, suffered multiple clinical fractures, and were on combination long and short acting opioids at the time of presentation. Two were in wheelchairs and two had neuropathy.

All patients had hypogonadism and proteinuria and case 1 had glycosuria. All patients had normal $25-\mathrm{OH}$ vitamin D, vitamin B12, $\mathrm{PTH}$, serum protein electrophoresis, magnesium, CBC, calcium, CPK, sedimentation rate, TSH. Case 1 had fractures of the hip, sacrum, and humerus; case 2 hip and ribs; and case 3 ribs, pelvis and knee. The technetium bone scan showed a similar pattern of increased uptake in multiple ribs, calcaneus, metatarsal bones, knees, and 


\begin{tabular}{lccccccccccccc}
\hline Case & Age & HIV, Y & TN, Y & Sx & VAS & BMI & alkphos & PO4 & Cr & K+ & NTX & FemN & LS \\
\hline 1 & 49 & 10 & 4 & 8 & 80 & 20.4 & 309 & 2.2 & 1.80 & 2.9 & 128 & -3.5 & -4.2 \\
2 & 69 & 32 & 10 & 8 & 70 & 18.0 & 245 & 1.5 & 1.33 & 4.2 & 57 & -2.6 & -2.3 \\
3 & 61 & 30 & 7 & 36 & 84 & 20.0 & 576 & 1.2 & 1.18 & 3.3 & 98 & -3.2 & -3.8
\end{tabular}

$\mathrm{Y}=$ years, $\mathrm{Sx}=$ symptoms in months, VAS = visual analogue scale, alkphos = alkaline phosphatase $(39-117 \mathrm{IU} / \mathrm{L}), \mathrm{PO} 4=$ phosphorus $(2.5-4.5 \mathrm{mg} / \mathrm{dL}), \mathrm{Cr}=$ creatinine $(0.76-1.27 \mathrm{mg} / \mathrm{dL})$, $\mathrm{K}_{+}=$potassium $(3.5-5.2 \mathrm{mml} / \mathrm{L})$, FemN $=$ femoral neck $\mathrm{T}$-score, $\mathrm{LS}=$ lumbar spine T-score.

sacrum in all three patients. A MRI of the knee showed bone marrow edema in case 2 and an atypical longitudinal fracture of the femur in case 3 . Tenofovir was withdrawn, oral phosphates given, and resolution of pain and biochemical changes occurred in 4-8 months. Bone mineral density in case 1 repeated 1 year after presentation increased $16 \%$ in the femoral neck and $19 \%$ in the lumbar spine.

The laboratory and clinical features in our cases shared with those previously reported include long duration of HIV and tenofovir treamtent, severe pain and disability, low BMI, neuropathy, hypogonadism in men, elevation of alkaline phoshatase and varying degrees of renal tubular dysfunction.

Conclusions: Long term tenofovir therapy in HIV patients can induce a devastating disabling osteomalacia caused by hypophosphatemia with features of Fanconi syndrome with or without vitamin D deficiency. A long standing history of HIV infection, low BMI, neuropathy, and hypogonadism in male patients may predispose or be associated with this complication. A serum phosphorus, alkaline phosphatase, and urinalysis should be followed regularly in all tenofovir treated patients to avoid the consequences of osteomalacia.

References:

[1] Karras A, et al, Clin Infect Dis 2003; 36:1070-1072.

[2] Earle KE, et al, J Bone Miner Dis 2004; 19:714-721.

[3] Mateo L, et al, Clin Rheumatol 2016; 35:1271-1279.

Disclosure of Interest: None declared

DOI: 10.1136/annrheumdis-2017-eular.2644

\section{AB0889 FACTORS CONTRIBUTING TO LENGTH OF INPATIENT HOSPITAL STAY FOR PATIENTS WITH ACUTE GOUT ARTHROPATHY AT THE NORTHERN HOSPITAL: AN OBSERVATIONAL STUDY}

M. Mian $^{1,2}$, M.N. Hossain ${ }^{3}$, M. Omair ${ }^{1}$, D. Liew ${ }^{1,2}$, C.E. Owen ${ }^{1,4}$, A.M. Foote $^{1,2}$ R.R.C. Buchanan 1,2,4 . ${ }^{1}$ Department of Medicine, Austin Health; ${ }^{2}$ Department of Medicine, Northern Health; ${ }^{3}$ School of Public Health and Preventive Medicine, Monash University; ${ }^{4}$ Department of Medicine, University of Melbourne, Melbourne, Australia

Background: Gout is a common inflammatory arthropathy with a reported prevalence ranging from $1.7 \%$ to $4 \%$ within Australia - one of the highest in the world, second only to New Zealand. ${ }^{1}$ Epidemiological studies have established that its prevalence has increased steadily over recent years, with the impact of the disease on the rise. ${ }^{2}$

Gout has painful and debilitating effects on patients leading to impact on their quality of life. Even though usually managed in the primary care setting, many patients are ultimately admitted as inpatients to hospital with the associated increased resource utilisation and cost. There is a growing recognition of the economic burden of gout. ${ }^{3}$ A Canadian study estimated 5-year total health costs of patients with gout at $\$ 10,332$ more than comparable gout free patients. ${ }^{4}$ Objectives: To identify factors potentially contributing to increased length of inpatient hospital stay for acute exacerbations of gout in a teaching hospital in Melbourne, Australia.

Methods: Patients admitted to The Northern Hospital, Melbourne, Australia with a discharge diagnosis of gout as their only acute medical problem between 1st July 2014 and 30th June 2016 were identified using ICD-10 disease coding from institutional compensation reports. Retrospective chart review was performed identifying length of stay and for variables which may potentially affect it.

Results: 121 patients were discharged with an acute gout flare over the 2 years with a mean age of $66 \pm 15$ years. The vast majority of patients in this cohort were male (86\%). The mean length of stay was 2.3 days (95\% Cl 1.83-2.78 days), with a median of 1 day. The median length of hospital stay was increased by 2 days if patients lived alone $(p=0.042)$ and 1 extra day if the $\mathrm{C}$-Reactive Protein (CRP) measured at admission was $>100 \mathrm{mg} / \mathrm{L}(p=0.001)$. Hospital stay was similarly prolonged by a single day if more than one joint was involved in the flare $(p=0.003)$.

Conclusions: Gout without antecedent acute medical comorbidity is a common acute medical presentation to hospital with a large corresponding economic burden. Factors affecting length of inpatient stay include social status, marked elevation of CRP and polyarticular involvement. This study identifies factors which warrant further investigation as to how they may be ameliorated in order to improve health resource utilisation.

\section{References:}

[1] Smit E, Hoy D, Cross $M$ et al. Burden of disability due to musculoskeletal (MSK) disorders. Ann Rheum Dis 2014; 73: 1470-1476.

[2] Becker MA. Recent developments in the management of gout. Rheumatology 2012;51:i1.

[3] Shields GE, Beard SM. A systematic review of the economic and humanistic burden of gout. PharmacoEconomics 2015;33: 1029-1047.
[4] Fischer A, Cloutier M, Goodfield J, Borrelli R, Marvin D, Dziarmaga A. The direct economic burden of gout in an elderly Canadian population. J Rheumatol 2017;44(1):95-101.

Disclosure of Interest: None declared

DOI: 10.1136/annrheumdis-2017-eular.5632

\section{AB0890 SYSTEMIC LUPUS ERYTHEMATOSUS AND GOUT: REALLY AN UNUSUAL ASSOCIATION?}

$\underline{\text { N. Quilis }}{ }^{1}$, M. Andrés ${ }^{2,3} .{ }^{1}$ Seccion de Reumatologia, Hospital Universitario Vinalopó, Elche; ${ }^{2}$ Seccion de Reumatologia, Hospital General Universitario de Alicante; ${ }^{3}$ Departamento de Medicina Clínica, Universidad Miguel Hernández, Alicante, Spain

Background: Patients with systemic lupus erythematosus (SLE) often suffer from cardiovascular comorbidity such as hypertension, dyslipidemia or coronary heart disease. However, the association with gout - an independent cardiovascular risk factor - is considered unusual - it is not reported in the EULAR textbook (1)-, and might not be taken into account when acute arthritis occurs in SLE patients, also due to the predominance of women in this disease.

Objectives: To review our experience regarding SLE patients who developed gout, and to perform a literature review of reported cases to date.

Methods: Retrospective review of patients with SLE and crystal-proven gout in our Rheumatology Unit, a tertiary care center. We recorded clinical and laboratory variables related to both diseases. Then, we performed a bibliographical review in Pubmed (1965 - 2016) to identify reported cases of coexistence of both diseases. Results: Out 189 SLE patients seen in our Unit, we have identified two cases with crystal-proven gout: 1) A 68 years-old woman with SLE and nephritis diagnosed 30 years ago, who developed polyarthritis affecting her hands. 2) A 47 years-old man with lupus for 22 years with nephritis and renal failure, who developed acute arthritis involving right knee and ankle. In both cases, urate crystals were demonstrated at synovial fluid. The table shows the results of the literature review together with our two cases. To date, 36 cases with coexistent SLE and gout have been reported. Median age at time of gout diagnosis was 43.5 years (p25-75 32.5-52.0), being 26 females (72\%). SUA levels were found notably high (median $13.5 \mathrm{mg} / \mathrm{dL}$ ), and tophi, a marker of gout severity, were demonstrated in almost half of cases $(44.4 \%)$. The majority of patients $(91 \%)$ were on glucocorticoids at time of gout diagnosis. According to common factors leading to hyperuricemia, lupus-related renal damage ( $86 \%$ ) and use of diuretics $(83 \%)$ predominated in the series.

\begin{tabular}{|c|c|c|c|c|c|c|c|c|c|}
\hline Ref. & $\begin{array}{c}\text { Sex \& } \\
\text { Age } \\
\text { (years) } \\
\end{array}$ & $\begin{array}{c}\text { Lupus } \\
\text { Nephritis }\end{array}$ & Diuretics & Corticoids & $\begin{array}{c}\text { Time between } \\
\text { SLE and gout } \\
\text { diagnoses (years) } \\
\end{array}$ & $\begin{array}{c}\text { Acute } \\
\text { arthritis }\end{array}$ & Tophi & $\begin{array}{l}\text { SUA at } \\
\text { diagnosis } \\
\text { (mg/dL) }\end{array}$ & $\begin{array}{l}\text { Other crystals } \\
\text { in synovial fluid }\end{array}$ \\
\hline \multirow{2}{*}{ Quilis 2017 } & $F 65$ & Yes & No & No & 30 & Yes & No & 11.1 & No \\
\hline & M 47 & Yes & No & No & 22 & Yes & No & 12.2 & No \\
\hline \multirow{3}{*}{ 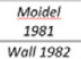 } & M 48 & Yes & Yes & Yes & 11 & Yes & No & 10.8 & No \\
\hline & F 39 & Yes & Yes & $?$ & 10 & $?$ & Yes & 12 & No \\
\hline & M 45 & Yes & Yes & Yes & 10 & Yes & No & 8.8 & No \\
\hline Rose 1982 & $F 34$ & No & No & Yes & 1,5 & Yes & No & $?$ & $\begin{array}{l}\text { CPP, } \\
\text { hydroxyapatite }\end{array}$ \\
\hline $\begin{array}{c}\text { Helliwell } \\
1982\end{array}$ & M 39 & Yes & $?$ & Yes & 12 & Yes & Yes & 14.8 & No \\
\hline Lally 1982 & F 29 & Yes & Yes & Yes & 9 & Yes & No & 10.2 & No \\
\hline \multirow{2}{*}{$\begin{array}{c}\text { Bradley } \\
1983 \\
\end{array}$} & F 31 & Yes & Yes & Yes & 4 & Yes & Yes & 16.5 & No \\
\hline & F 57 & Yes & $?$ & Yes & 20 & Yes & Yes & 9.5 & No \\
\hline $\begin{array}{c}\text { Rodriguez } \\
1984\end{array}$ & F 17 & Yes & Yes & Yes & 5 & No & Yes & 12 & $\begin{array}{l}\text { CPP, } \\
\text { hydroxyapatite, } \\
\text { cholesterol }\end{array}$ \\
\hline \multirow{2}{*}{$\begin{array}{c}\text { Greenfield } \\
1985\end{array}$} & F56 & Yes & Yes & Yes & 12 & Yes & No & 13.18 & No \\
\hline & M41 & Yes & Yes & Yes & 14 & Yes & No & 9 & No \\
\hline $\begin{array}{c}\frac{T \text { suboi }}{1986} \\
\end{array}$ & F 25 & Yes & Yes & Yes & 7 & No & Yes & 12.2 & No \\
\hline $\begin{array}{l}\text { Erocht } \\
1987 \\
\end{array}$ & F 37 & Yes & Yes & Yes & 7 & Yes & No & 12.9 & No \\
\hline $\begin{array}{c}\text { McDonold } \\
1988\end{array}$ & M 43 & Yes & Yes & Yes & 10 & No & Yes & 8.3-10.8 & No \\
\hline $\begin{array}{c}\text { Kalmar } \\
1982 \\
\end{array}$ & F 4 7 & Yes & Yes & Yes & 6 & No & Yes & 16.1 & No \\
\hline $\begin{array}{c}\text { Alarcon } \\
1983 \\
\end{array}$ & 552 & No & ? & ? & 14 & Yes & No & 18 & No \\
\hline Kurito 1989 & F 37 & Yes & Yes & Yes & 15 & No & Yes & 11.4 & No \\
\hline \multirow{3}{*}{$\begin{array}{c}\text { Veerapen } \\
1993\end{array}$} & $F 31$ & Yes & $?$ & Yes & 11 & Yes & Yes & 11.5 & No \\
\hline & M 24 & Yes & Yes & Yes & 6 & Yes & Yes & 15 & No \\
\hline & M 22 & Yes & Yes & Yes & 4 & Yes & Yes & 10.1 & No \\
\hline $\begin{array}{c}\text { McMillen } \\
1994\end{array}$ & F 52 & Yes & $?$ & Yes & 7 & Yes & No & 6.9 & No \\
\hline \multirow[t]{7}{*}{ Ho 2003} & $F 61$ & No & Yes & Yes & 6 & Yes & Yes & 17.3 & No \\
\hline & F 37 & Yes & Yes & Yes & 5 & Yes & Yes & 17.5 & No \\
\hline & F 30 & No & Yes & Yes & 8 & Yes & No & 12.9 & No \\
\hline & F 50 & Yes & Yes & Yes & 13 & Yes & Yes & 10.3 & No \\
\hline & F 68 & Yes & Yes & Yes & 4 & Yes & No & 9.9 & No \\
\hline & $F 77$ & No & Yes & Yes & 14 & Yes & Yes & 9.2 & No \\
\hline & F33 & Yes & Yes & Yes & 7 & Yes & No & 11.2 & No \\
\hline \multirow[t]{6}{*}{ Bajoj 2004} & F 22 & Yes & No & Yes & 9 & $?$ & $?$ & 18.4 & No \\
\hline & $F 44$ & Yes & Yes & Yes & 10 & ? & $?$ & 15.1 & No \\
\hline & M 46 & Yes & Yes & Yes & 9 & $?$ & $?$ & 15.1 & No \\
\hline & M 47 & Yes & No & Yes & 31 & $?$ & $?$ & 13.4 & No \\
\hline & $\mathrm{FS3}$ & Yes & Yes & No & 4 & $?$ & $?$ & 15.1 & No \\
\hline & F55 & Yes & Yes & Yes & 21 & $?$ & $?$ & 6.7 & No \\
\hline
\end{tabular}

Conclusions: Data supports including gout into the differential diagnosis of episodes of acute arthritis in SLE patients. This makes crucial the routine analysis of all synovial fluid samples, but especially in patients with long-term disease, renal impairment, and diuretic use.

References:

[1] EULAR Textbook on Rheumatic Diseases. BMJ, 2015.

Disclosure of Interest: None declared

DOI: 10.1136/annrheumdis-2017-eular.5292 